\title{
DATA SCIENCE AS DECISION MAKING SUPPORT FOR CREATING SUCCESSFUL CROWDFUNDING CAMPAIGNS: LESSONS LEARNED FROM KICKSTARTER
}

Nikola Stevanović

Singidunum University,

Belgrade, Serbia
Correspondence:

Nikola Stevanović

e-mail:

nrstevanovic@gmail.com

\begin{abstract}
:
Crowdfunding presents an opportunity for entrepreneurs to launch their ventures or to scale them globally without having to rely on traditional funding. The request for raising funds and other possible resources through social media and direct communication with prospective buyers and investors are key factors that differ it from the conventional financing. There are more than thousand projects that are being opened every single day on different crowdfunding platforms and their success depends on certain factors. There are factors that people may be aware of, but to be certain, only analysis of the previous campaigns can show what the factors that contribute to the project success are and which road should people take in order to raise higher amount of money. Data science is an arising interdisciplinary field that has its root in statistics and mathematics, and along with them it draws its theories from information and computer sciences. Its process consists of gathering and processing data in order for further exploratory analysis, and other processes that will eventually lead to data driven decision making that should be of higher quality than decision making lead by the rule of thumb. This research paper offers indirect outline which project is supposed to follow in order to become successfully financed on Kickstarter crowdfunding platform. The paper focuses on the first insights we have gained from more than 250.000 projects that were started on this platform thus giving valuable information that may be used to estimate the success of the future ones.
\end{abstract}

Keywords:

crowdfunding, Kickstarter, data driven decision making, alternative financing, data science.

\section{INTRODUCTION}

Crowdfunding presents a new way for entrepreneurs to raise funds for their projects, without need to rely on traditional funding systems such as banks. It is currently on the growth, getting more popularity each day, thus leading to more money being invested in the projects that are started this way. Beginning of the crowdfunding as we know it now is connected to the launch of Artistshare platform in 2003. It has been followed by other platforms, some of which are now recognized and famous IndieGoGo (2008) and Kickstarter (2009). Crowdfunding, as stated in [1] has been widely used since then to fund wide range for-profit entrepreneurial ventures such as artistic and creative projects, medical expenses, travel or community-oriented social entrepreneurship projects. 
After the initial hype and rush, logical step in every field is to analyze what happened and how it happened in order to make better decision in the future, or to at least leave impression that that is what you are doing. In order for that to happen first step would be acquiring the essential data. That is the moment when the data science comes at play.

Data science is, according to an early and one of the first definitions in [2], a concept to unify statistics, data analysis, and their related methods in order to understand and analyze actual phenomena with data. If we take a look from a more modern point of view, we may say that data science is an interdisciplinary field focused on scientific methods, processes and systems to extract knowledge or insights from data in various forms, structured or unstructured, according to Jeff Leek prominent professor in traditional and modern (massive online open course) terms in [3]. Kickstarter platform is used as initial platform for gaining first insights on how the crowdfunding process works and its successfulness.

\section{CROWDFUNDING: A BRIEF SUMMARY}

\section{Concept}

Crowdfunding is a method for funding new ventures or social/private causes allowing founder i.e. creators of any type of project to request funding from many individuals, often in return for future products or equity. Projects themselves can range greatly in both goal and magnitude, from small projects that are not profitable, yet have huge importance to their creators, to the multimillion dollar projects that are aimed to large group of people. Persons that invest money this way usually receive some kind of incentive to do so in the first place, that can be either preordering of the stuff that is yet to be created or made or similar.

\section{Types of crowdfunding}

The Crowdfunding Centre's May 2014 report identified two primary types of crowdfunding: reward crowdfunding and equity crowdfunding, although debt based is gaining more popularity in corporate setting, and donation based in charity setting respectively.

Reward crowdfunding presents entrepreneurs who presell a product or service to launch a business concept without incurring debt or sacrificing equity/shares. This concept is the most popular one and is widely used by major crowdfunding platforms.
Equity crowdfunding presents the backer who receives shares of a company, usually in its early stages in exchange for the money pledged. Equity crowdfunding is the collective effort of individuals to support efforts initiated by other people or organizations through the provision of finance in the form of equity.

Debt-based crowdfunding (also known as "crowdlending") functions on principle that Borrowers apply online, generally for free, and their application is reviewed and verified by an automated system, which also determines the borrower's credit risk and interest rate. Investors buy securities in a fund which makes the loans to individual borrowers or bundles of borrowers. Investors make money from interest on the unsecured loans; the system operators make money by taking a percentage of the loan and a loan servicing fee.

Donation-based is charity oriented crowdfunding where the collective effort of individuals is to help charitable causes.

\section{DATA SCIENCE - APPROACH AND OUTLINES}

\section{Historical view- important dates}

The term data science was first included in the name of the conference in 1996, when members of the International Federation of Classification Societies (IFCS) met in Kobe for their biennial conference ("Data Science, classification, and related methods") after the term was introduced in a roundtable discussion by Chikio Hayashi in [1] Before you begin to format your paper, first write and save the content as a separate text file. Keep your text and graphic files separate until after the text has been formatted and styled. Do not use hard tabs, and limit use of hard returns to only one return at the end of a paragraph. Do not add any kind of pagination anywhere in the paper. Do not number text heads-the template will do that for you.

In 2001, William S. Cleveland in [4] introduced data science as an independent discipline, extending the field of statistics to incorporate "advances in computing with data" in his article "Data Science: An Action Plan for Expanding the Technical Areas of the Field of Statistics," which was published in Volume 69, No. 1, of the April 2001 edition of the International Statistical Review / Revue Internationale de Statistique. In his report, Cleveland establishes six technical areas which he believed to encompass the field of data science: multidisciplinary investigations, models and methods for data, computing with data, pedagogy, tool evaluation, and theory. 


\section{Data Science - From Data to Insight}

Every data science process starts with collecting raw data from real life environment. Taking into consideration that more is better, and that large samples are highly valued, automatization of scraping process plays a huge part at this first step.

After the initial acquiring of the data the next step is processing in order to get a grasp of what research does have, removing outliers and other material that is of no value and that can be disturbance and omit results.

Exploratory data analysis is what most people think of data analysis and that is the moment when research can see some first insights that are supported by facts and figures.

Decision making is the last step in the process and in order for it to happen it is necessary to communicate visualize report so decision makers could see a whole picture and understand what change will drive desired outcome.

\section{KICKSTARTER - CROWDFUNDING PLATFORM}

\section{How it all began}

Kickstarter is launched in 2009. and shortly after that it was named as one of the" Best inventions of 2010" and "Best Websites of 2011" by Time magazine. Kickstarter is currently largest crowdfunding platforms in the world, regarding the number of projects that got open every day and money that is attracted on it. It is one of the many platforms that exist these days and whose purpose is to gather money from the public in a nontraditional way. Since its debut in 2009. Kickstarter popularity is on the rise, and at the end of 2016. it looked like this, according to [5], and reported by platform itself in that period.

\begin{tabular}{rcccc}
\hline $\begin{array}{c}\text { Total amount of } \\
\text { dollars pledged to } \\
\text { Kickstarter projects }\end{array}$ & $\begin{array}{c}\text { Successfully funded } \\
\text { projects }\end{array}$ & Total backers & Repeat backers & Total pledges \\
\hline$\$ 2.759 .893 .417$ & 116.013 & 12.086 .881 & 3.839 .956 & 34.781 .312 \\
\hline
\end{tabular}

Table 1. Facts and figures regarding projects support

Current business model proposition that platform uses is oriented toward self-sustainability. In order for reaching that Kickstarter is imposing 5\% fee on successfully funded projects, plus the payment processing fee that varies between 3-5\% depending on the country that backers reside in polarity versus successfulness.

Decision making is the last step in the process and in order for it to happen it is necessary to communicate visualize report so decision makers could see a whole picture and understand what change will drive desired outcome.

\section{Project categories}

Crowdfunding platforms like this have high exposure to the general public and that leads to the large potential base of backers that may support projects. Its number and names were changing over times, but current categories that Kickstarter serves are: Film \& Video, Music, Publishing, Technology, Games, Food, Design, Art, Fashion, Photography, Crafts, Comics, Theatre, Journalism and Dance.

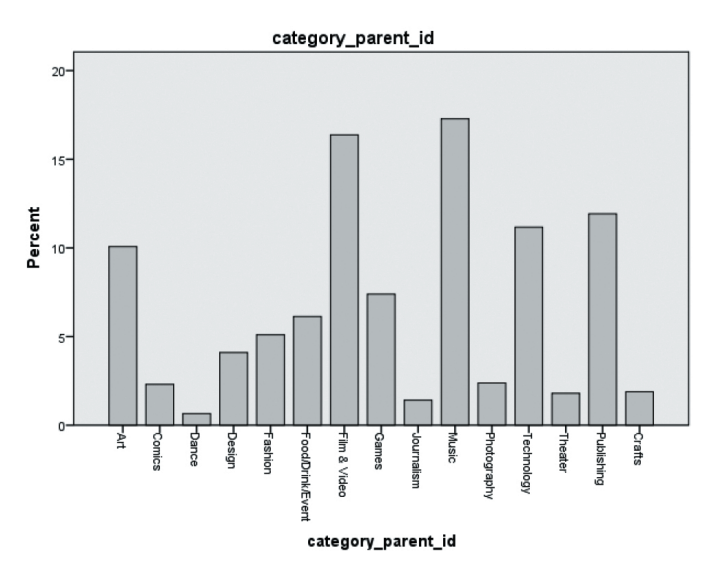

Fig. 1. Project categories and their represantation on Kickstarter platform

As the data shows available in dataset, and on Kickstarter website shows, Music and Film \& Video are parent categories that have had the highest number of successful project. On the same note, it is of importance to mention that their number of unsuccessful project is the highest one as well. 


\begin{tabular}{|c|c|c|c|c|c|c|c|}
\hline & & canceled & failed & live & successful & suspended & Total \\
\hline \multirow[t]{15}{*}{ category_parent_id } & Art & 1254 & 8113 & 163 & 6564 & 46 & 16140 \\
\hline & Comics & 292 & 1293 & 139 & 1950 & 13 & 3687 \\
\hline & Dance & 46 & 414 & 14 & 561 & 10 & 1045 \\
\hline & Design & 270 & 1521 & 413 & 4347 & 17 & 6568 \\
\hline & Fashion & 522 & 5409 & 242 & 1950 & 52 & 8175 \\
\hline & Food/DrinkEvent & 935 & 6623 & 190 & 1993 & 75 & 9816 \\
\hline & Film \& Video & 1228 & 10406 & 404 & 14143 & 41 & 26222 \\
\hline & Games & 712 & 4107 & 464 & 6475 & 82 & 11840 \\
\hline & Journalism & 249 & 1540 & 46 & 402 & 28 & 2265 \\
\hline & Music & 1480 & 10355 & 286 & 15493 & 69 & 27683 \\
\hline & Photography & 387 & 2337 & 69 & 999 & 29 & 3821 \\
\hline & Technology & 2118 & 11499 & 435 & 3645 & 191 & 17888 \\
\hline & Theater & 191 & 1045 & 48 & 1590 & 8 & 2882 \\
\hline & Publishing & 610 & 9716 & 354 & 8386 & 23 & 19089 \\
\hline & Crats & 286 & 1966 & 64 & 672 & 34 & 3022 \\
\hline Total & & 10580 & 76344 & 3331 & 69170 & 718 & 160143 \\
\hline
\end{tabular}

Table 2. Relation between category and project outcome

\section{Polarity as the factor for project success}

In order for gaining attention and promote themselves to their prospective audience, project creators have to fulfill certain steps. One of the basic ones and the required one is for them to write a small "blurb" about the core idea of the project. It is supposed to be straight to the point and to present the project in the best way so that the people can become curious to learn more about the project, read additional article, watch video if available, check other materials and eventually back i.e. support the project. As it can be seen in Table 3. people are aware that negative sentiment can affect success of their campaigns so they tend to leave a positive tone in their presentation.

\begin{tabular}{|c|c|c|c|c|}
\hline & Frequency & Percent & $\begin{array}{c}\text { Valid } \\
\text { Percent }\end{array}$ & $\begin{array}{c}\text { Cumulative } \\
\text { Percent }\end{array}$ \\
\hline $\begin{array}{l}\text { Missing required } \\
\text { parameter(s) - [txt] }\end{array}$ & 1 & 0 & 0 & 0 \\
\hline Insufficient parameters & 19 &, 0 &, 0 &, 0 \\
\hline $\mathrm{N}$ & 14905 & 9,3 & 9,3 & 9,3 \\
\hline N+ & 4030 & 2,5 & 2,5 & 11,8 \\
\hline NEU & 7863 & 4,9 & 4,9 & 16,7 \\
\hline NONE & 30507 & 19,0 & 19,0 & 35,8 \\
\hline$P$ & 82771 & 51,7 & 51,7 & 87,5 \\
\hline $\mathbf{P}+$ & 20047 & 12,5 & 12,5 & 100,0 \\
\hline Total & 160143 & 100,0 & 100,0 & \\
\hline
\end{tabular}

Table 3. Projects polarity based on their blurb

As the data shows in Table 4. we can see that projects that had positive sentiment had the highest number of successful projects, and on the other side ones that had negative sentiment had the lowest number of successful projects. On that note the data shows that relation between successful and failed project across different sentiments doesn't oscillate that much, which opens the question what are the additional factors that may try to minimize this factor.

\begin{tabular}{|l|r|r|r|r|r|}
\hline \multirow{2}{*}{} & \multicolumn{5}{|c|}{ Outcome } \\
\cline { 2 - 6 } & canceled & failed & live & successful & suspended \\
\cline { 2 - 6 } & Count & Count & Count & Count & Count \\
\hline 200 - Missing required & & & & & \\
parameter(s) - [txt] & 1 & 0 & 0 & 0 & 0 \\
202 - Engine internal & & & & & \\
error & 1 & 11 & 1 & 6 & 0 \\
N & & & & & \\
N+ & 226 & 6552 & 331 & 7072 & 72 \\
NEU & 487 & 3623 & 152 & 3560 & 41 \\
NONE & 2122 & 14259 & 601 & 13397 & 128 \\
P & 5468 & 40295 & 1702 & 34936 & 370 \\
P+ & 1397 & 9791 & 448 & 8321 & 90 \\
\hline
\end{tabular}

Table 4. Projects outcomes in relation with their polarity

\section{CONCLUSION}

Crowdfunding is improving the way in which people are getting the funding from the interested parties in order for their ideas to be brought to life. Different types of platforms and wide range of categories on them provide infinite number of possibilities to entrepreneurs. In order for projects to be successful their creators have to aware what resonates best with their audience. For that they need to present their idea in the way that will leave positive impression, and sentiment that will engage people. The further research on acquired dataset and its update with new cases will try to show us the meaningful connections between different factors that are influencing the success of the projects and to see in depth what factors may affect sentiment and lower its sole effect on success of the crowdfunding campaigns. 


\section{REFERENCES}

[1] R. Gleasure, J. Feller, Emerging technologies and the democratization of financial services: A metatriangulation of crowdfunding research. Information and Organization, 26(4), 2016, pp 101-115

[2] C. Hayashi, What is Data Science? Fundamental Concepts and a Heuristic Example, in C. Hayashi, K. Yajima, H.H. Bock, N Ohsumi, Y. Tanaka, Y. Baba, Data Science, Classification, and Related Methods. Studies in Classification, Data Analysis, and Knowledge Organization. Springer Japan, 1998 pp. $40-51$.
[3] J. Leek, The key word in "Data Science" is not Data, it is Science, 2013, Simply Statistics. accessed on 28th Feb. 2017

[4] W. S. Cleveland, Data science: an action plan for expanding the technical areas of the field of statistics, International Statistical Review / Revue Internationale de Statistique, 2006, pp 21-26

[5] N. Stevanovic, Crowdfunding - an alternative approach to global financing with emphasize on kickstarter platform, Third international scientificbusiness conference leadership \& management: integrated politics of research and innovation - Limen 2016, 2016, in press 